\title{
Modification In Fixture Design For Telescopic Shaft Which Manufacturing On Milling Machine
}

\author{
Mohnesh Mandhre', Sajjadshah Sayyad² ${ }^{1}$ Imran Shaikh³ ${ }^{3}$,Shubham Zarekar ${ }^{4}$ \\ Alina Beg 5 \\ ${ }^{1}$ Assistant Professor, Mechanical Engineering, Shri Chhatrapati Shivaji Maharaj COE, Ahmednagar, Maharashtra \\ ${ }^{2-5}$ UG - Mechanical Engineering, Shri Chhatrapati Shivaji Maharaj COE, Ahmednagar, Maharashtra
}

\begin{abstract}
Telescopic shaft is very important part of machine. It should be accurately machined with the acceptable tolerance. Also the fluctuations of dimensions in work-piece to work piece should be minimum so that it will be easier to assemble in machine. But it has been observed that the required dimensions for the larger end diameter and smaller end diameter for the telescopic shaft are not continuously achievable by using the existing fixture.

In machining fixtures, minimizing workpiece deformation due to clamping and cutting forces is essential to maintain the machining accuracy. Fixture is required in various industries according to their application. This can be achieved by selecting the optimal location of fixturing elements such as locators and clamps.

The fixture set up for component is done manually. For that more cycle time required for loading and unloading the material. So, there is need to develop system which can help in improving productivity and time. Fixtures reduce operation time and increases productivity and high quality of operation is possible.The proposed fixture will fulfilled researcher production target and enhanced the efficiency, reduces operation time and increases productivity, high quality of operation, reduce accidents.
\end{abstract}

Keywords: Telescopic Shaft, Fixture Design, Production Rate.

\section{INTRODUCTION}

The fixture is a special tool for holding a work piece in proper position during manufacturing operation. For supporting and clamping the work piece, device is provided. Frequent checking, positioning, individual marking and non-uniform quality in manufacturing process is eliminated by fixture.

This increase productivity and reduce operation time. Fixture is widely used in the industry practical production because of feature and advantages to locate and immobilize work pieces for machining, inspection, assembly and other operations fixtures are used.

A fixture consists of a set of locators and clamps. Locators are used to determine the position and orientation of a work piece, whereas clamps exert clamping forces so that the work piece is pressed firmly against locators. Clamping has to be appropriately planned at the stage of machining fixture design.

The design of a fixture is a highly complex and intuitive process, which require knowledge. Fixture design plays an important role at the setup planning phase. Proper fixture design is crucial for developing product quality in different terms of accuracy, surface finish and precision of the machined parts in existing design the fixture set up is done manually, so the aim of this paper is to replace with hydraulic fixture to save time for loading and unloading of component.

Hydraulic fixture provides for flexibility in holding forces and to optimize design for machine operation as well as process function ability. 
International Advanced Research Journal in Science, Engineering and Technology

Impact Factor $7.105 \div$ Vol. 9, Issue 1, January 2022

DOI: $10.17148 /$ IARJSET.2022.9150

\section{EXPERIMENTAL METHODS OR METHODOLOGY}

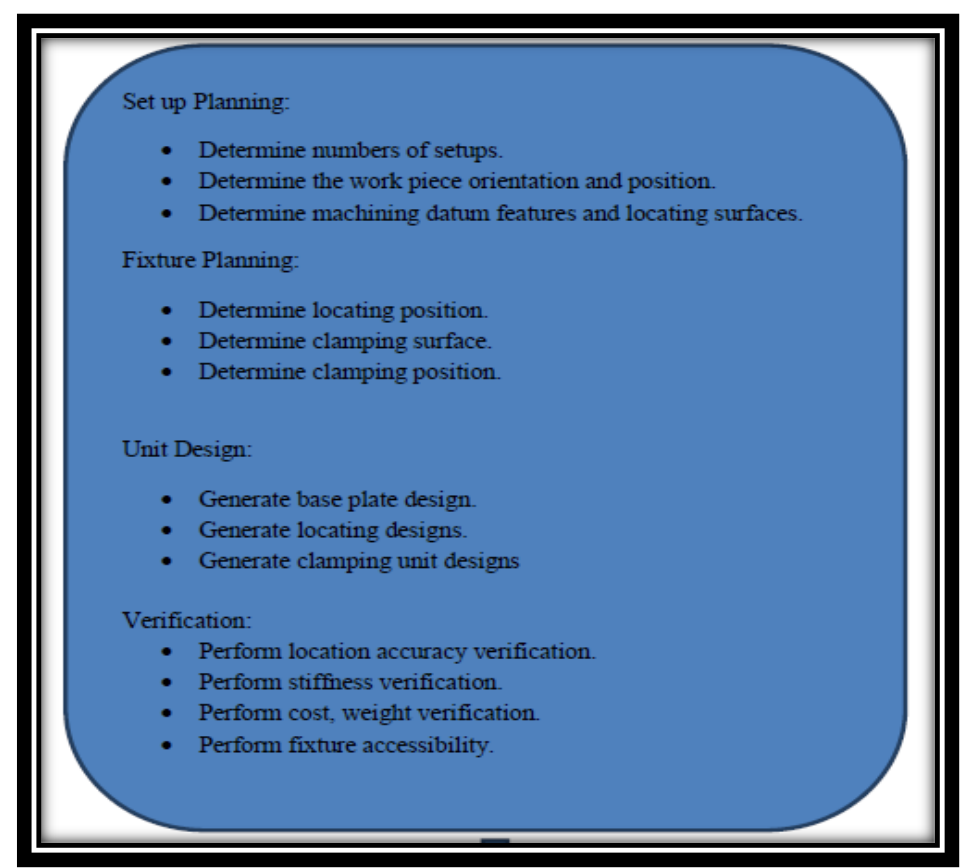

Fig 1. Procedure for Fixture Design

\section{IMPORTANT CONSIDERATIONS WHILE DESIGNING FIXTURES}

1. Study of workpiece and finished component size and geometry.

2. Type and capacity of the machine, its extent of automation.

3. Provision of locating devices in the machine.

4. Available clamping arrangements in the machine.

5. Available indexing devices, their accuracy.

6. Evaluation of variability in the performance results of the machine.

7. Rigidity and of the machine tool under consideration.

8. Study of ejecting devices, safety devices, etc.

9. Required level of the accuracy in the work and quality to be produced.

\subsection{Elements of Fixture}

Generally, all fixtures consist of the following elements:

\section{Locators}

A locator is usually a fixed component of a fixture. It is used to establish and maintain the position of a part in the fixture by constraining the movement of the part. For work pieces of greater variability in shapes and surface conditions, a locator can also be adjustable.

\section{i.Vee Locators}

This is quick and effective method of locating the workpiece with desired level of accuracy. This is used for locating the circular and semi-circular type of workpiece. The main part of locating device is Vee shaped block which is normally fixed.

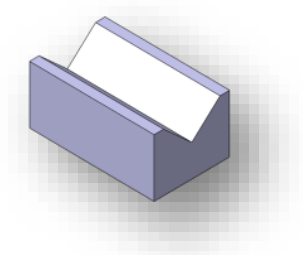

Fig. 2 VEE Shaped Locator 


\section{International Advanced Research Journal in Science, Engineering and Technology \\ Impact Factor 7.105 Vol. 9, Issue 1, January 2022 \\ DOI: $10.17148 / I A R J S E T .2022 .9150$}

\section{Clamps}

A clamp is a force-actuating mechanism of a fixture. The forces exerted by the clamps hold a part securely in the fixture against all other external forces acting on to the component.

\section{Supports}

A support is a fixed or adjustable element of a fixture. When severe part displacement/ deflection is expected under the action of imposed clamping and processing forces, supports are added and placed below the work piece so as to pre vent or constrain deformation. Supports in excess of what is required for the determination of the location of the part should be compatible with the locators and clamps.

\subsection{General Requirements of Fixture}

In order to maintain the work piece stability during a machining process, an operational fixture has to satisfy several requirements to fully perform its functions as a work holding device. The following constraints must be observed while designing a viable fixture.

1. Geometric constraint

Geometric constraint guarantees that all fixture elements have an access to the datum surface. They also assure that the fixture components do not interfere with cutting tools during a machining operation. In addition to these requirements, a fixture design should have desirable characteristics such as quick loading and unloading, minimum number of components, accessibility, design for multiple cutting operations, portability, low cost, etc.

2. Contained deflection

Work piece deformation is unavoidable due to its elastic/plastic nature, and the external forces impacted by the clamping actuation and machining operations. Deformation has to be limited to an acceptable magnitude in order to achieve the tolerance specifications.

3. Deterministic location

The work piece is constrained by locators so that it is presentable for the machining operation. Locating errors due to locators and locating surfaces of the work piece should be minimized so as to accurately position the work piece within the machine coordinate frame.

\section{MATERIAL AND ITS SPECIFICATIONS}

D2: A cold work tool steel. D2 is a high chromium tool steel specifically designed to provide a high abrasive wear resistance and a high hardenability. The grade is delivered in annealed condition to keep a good machinability. After machining it requires a hardening to achieve its service properties. The adjustment of hardness should be done to get the best compromise between toughness and wear resistance. This grade can be used for cutting and deformation tools submitted to high abrasive wear. It can be used when 2\% carbon steels (D3 type) shows an excessive senility to cracking or chipping.

Main applications are stamping tools, punches and dies, forming dies, shear blades and cutters, ceramic molds.

\section{CALCULATIONS}

$\begin{array}{ll}\text { - } & \text { Dimensions of fixture } \\ \text { - } & \text { Internal diameter } 10.01 \mathrm{~mm} \\ \text { - } & \text { External diameter } 20 \mathrm{~mm} \\ \text { - } & \text { Stress = force/area } \\ \text { - } & \text { Foung's modulus of material is } 205 \mathrm{GPa} \\ \text { - } & \text { Length of rectangular section is } 50.20 \mathrm{~mm} \\ \text { Thickness of base plate is } 10 \mathrm{~mm}\end{array}$

\section{CONCLUSION}

The efficiency and reliability of the fixture design has enhanced by the system and the result of the fixture design has made more reasonable. To reduce cycle time required for loading and unloading of part, this approach is useful. If modern CAE, CAD are used in designing the systems then significant improvement can be assured. To fulfill the multifunctional and high performance fixturing requirements optimum design approach can be used to provide comprehensive analyses and determine an overall optimal design. Fixture layout and dynamic clamping forces optimization method based on optimal fixture layout could minimize the deformation and uniform the deformation most effectively. The proposed 


\section{International Advanced Research Journal in Science, Engineering and Technology \\ Impact Factor 7.105 ㄷ Vol. 9, Issue 1, January 2022 \\ DOI: 10.17148/IARJSET.2022.9150}

fixture will fulfilled researcher production target and enhanced the efficiency, Hydraulic fixture reduces operation time and increases productivity, high quality of operation, reduce accidents.

Traditionally, fixture design is a manual process and demands an expert's Knowledge and skilled engineering. . In this report, a literature survey of fixture design and automation over the past decade is proposed with the introduction on the fixture applications in industry and the significant works done in the design field, including their approaches, requirements and working principles are discussed. Finally, some prospective research trends are also discussed.

\section{REFERENCES}

1. Shivaji mengawade, vaibhav bankar, pratik p chaphale a review on design and analysis of work holding fixture April 2016

2. Sridharakeshava $\mathrm{k} \mathrm{b}$, ramesh babu. $\mathrm{K}$ advanced treatise on jigs and fixture design august 2013

3. Shailesh s.pachbhai, laukik p.raut a review on design of fixtures march 2014

4. Iain boyle cafixd - a case-based reasoning method for fixture design may 2006

5. Prof. mr. uday c. agashe, mr. adwait ranpise, mr. mayur mahajan, mr. anil shrirame study of fixture and its modifications April 2018 